\title{
Knowledge and attitudes towards Vitamin D food fortification
}

\begin{tabular}{|r|l|}
\hline Journal: & Nutrition and Food Science \\
\hline Manuscript ID & NFS-04-2018-0121.R2 \\
\hline Manuscript Type: & Original Article \\
\hline Keywords: & Vitamins, vitamin D, knowledge, Consumer Attitudes, fortification \\
\hline \multicolumn{2}{|l}{} \\
\end{tabular}

SCHOLARONE ${ }^{m}$

Manuscripts 
Knowledge of vitamin D

\section{Abstract}

2 Purpose: Vitamin D deficiency is a well-recognised public health problem within the UK,

3 with specific population groups more vulnerable to deficiency. Two pilot studies were used to 4 explore awareness of vitamin D deficiency and attitudes towards food fortification.

6 Methodology: A survey of 120 participants from five at risk groups (South Asians, Blacks,

7 Middle Eastern, Far Eastern and Caucasian older adults over 65 years) plus a group of British

8 Caucasians who do not avoid sun exposure, explored awareness of vitamin D, sun exposure

9 knowledge and behaviour, and attitudes towards food fortification. The latter group was

10 included to provide a comparison group who were at a reduced risk of deficiency. Chi-square

$11\left(\chi^{2}\right)$ was used to test associations between categorical variables and the study groups. The

12 second study utilized three focus groups and two interviews, conducted on young South

13 Asian females and examined knowledge and awareness of vitamin D and vitamin D fortified 14 foods.

16 Findings: A lack of knowledge and misconceptions were highlighted by both studies in 17 relation to at risk factors including sunlight exposure $(p=0.037)$, dietary intakes $(p=0.0174)$, 18 and darker skin pigmentation $(p=0.023)$, sources of vitamin $\mathrm{D}$ and the health benefits 19 associated with optimal consumption. Attitudes to mandatory fortification of some foods 20 varied significantly $(p=0.004)$ between the groups with acceptance rates for Blacks $(68 \%)$, 21 those over 65 years (50\%), Middle Eastern (67\%) and Far Eastern (73\%), whereas the control 22 (71\%) showed no acceptance, and South Asians gave a mixed response (48\% No). Focus 23 group findings highlighted positive views towards fortification although this was less for 24 mandatory as opposed to voluntary fortification. Both pilot studies highlight the need for 25 more research into this area, in order to create more effective public health policies. 
Knowledge of vitamin D

26

27 Originality/value: The research presents novel insights into a topical area where there is 28 limited research.

29

30

31 Key words: vitamin D deficiency, knowledge, consumer attitudes, fortification, at risk 32 groups

33

34 Classification:

research

paper 
Knowledge of vitamin D

\section{Introduction}

36 Vitamin D deficiency has gained great interest recently both in the UK and further afield 37 (Palacios and Gonzalez, 2014), with a number of new health conditions now being associated 38 with deficiency, which is on the increase globally (Borradale and Kimlin, 2009, Chowdhury 39 et al., 2014, Holick, 2017). The UK, and countries of similar latitude, are particularly 40 susceptible to vitamin D deficiency due to inadequate UVB-sunlight exposure from October 41 to April.

42 In addition to latitude, additional factors increase the risk of developing deficiency including; 43 aging, obesity, sunscreen use, cultural practices which cover the skin and darker skin 44 pigmentation, with individuals with higher amounts of melanin requiring longer sun exposure 45 to synthesise vitamin D (Battault et al., 2013, McAree et al., 2013, Reeder et al., 2012). This 46 is exacerbated when those with darker pigmentation migrate to northern latitudes such as 47 northern Europe, including the UK, making them more prone to vitamin D deficiency 48 (Ashwell et al., 2010, Kift et al., 2013, Meyer et al., 2008, Pearce and Cheetham, 2010).

49 As minimal vitamin D is synthesised during winter, a greater dependence on dietary sources 50 occurs (Cashman, 2007, Ashwell et al., 2010). UK dietary recommendations have been 51 reviewed and updated by the Scientific Advisory Committee on Nutrition (SACN, 2016) 52 calling for a Reference Nutrient Intake of $10 \mu \mathrm{g} /$ day for the vitamin for the first time, 53 including the elderly, pregnant and lactating women and those from ethnic groups who have 54 pigmented skin, where again $10 \mu \mathrm{g}$ /day is recommended. However, it has been suggested the 55 UK South Asian population are unaware of these recommendations (Farrar et al., 2011).

56 In the UK dietary sources include oily fish, egg yolk, and meat (Ashwell et al., 2010).

57 However, these foods are infrequently consumed (Cashman, 2012). Black et al. (2012)

58 propose a typical Western-style diet is currently unable to provide $10-20 \mu \mathrm{g}$ of vitamin 59 D/day, with evidence from the National Diet and Nutrition Surveys supporting this, with 
Knowledge of vitamin D

60 typical mean daily intakes being considerably lower than the Reference Nutrient Intake for

61 both children and the elderly (Bates et al., 2012).

62 There have been calls nationally among certain vitamin D researchers to introduce a more 63 comprehensive fortification of food with vitamin D policy in the UK where very few foods 64 are currently fortified. This position is in stark contrast to the fortification practices in the 65 USA and Canada where fortified foods are the main dietary source of vitamin D (Calvo and 66 Whiting, 2006). Furthermore, the introduction of the fortification of food with vitamin D of 67 all liquid dairy products and fat spreads in Finland in the mid 2000's has resulted in clear benefits to population vitamin D status (Boucher, 2012, Jääskeläinen et al., 2017), highlighting the potential for food fortification in addressing vitamin D deficiency.

Dietary staples such as milk, dairy products, juice, cereals and bread are typically fortified

71 with vitamin D (Kiely and Black, 2012). However, these will only target selected groups of 72 the population and do not take into account variations in dietary habits, which should be 73 considered (Black et al., 2012) especially for at risk groups who may have culturally diverse 74 dietary habits.

75 A review of fortification policy is becoming increasingly pertinent in light of the SACN 76 review. However, prior to any changes in food policy it is imperative to consider consumers 77 understanding of vitamin D and fortified foods, especially those most at risk of deficiency, so 78 as to develop effective public health policies.

79 There is very little information available regarding consumers' knowledge and awareness of 80 vitamin D and its dietary sources, especially in at risk groups of the population (Kung and 81 Lee, 2006). This project therefore describes two pilot studies that investigate awareness of 82 dietary vitamin D and attitudes towards food fortification among at risk groups living within 83 Newcastle-upon-Tyne, an area of the UK at increased risk of deficiency due to its latitude. 
Knowledge of vitamin D

85 Methodology

86

87

88

89

90

91

92

93

94

95

96

97

98

99

100

101

102

103

104

105

106

107

108

109

Introduction

Two pilot studies were used; the first to establish awareness and knowledge of vitamin D by means of a survey in five at risk groups of the population, and the second providing a more in-depth exploration of attitudes towards the fortification of food with vitamin D by means of both focus groups and interviews with one specific at-risk population group, so as to provide insights into barriers and drivers of acceptance of vitamin D fortified foods. Studies were conducted a year apart, with no individuals participating in both studies. Results of both studies are then discussed together in the discussion so as to provide greater insight into vitamin D awareness.

\section{Study 1: Quantitative Pilot Study}

The survey was adapted from a pre-existing questionnaire (Alemu and Varnam, 2012), being modified to meet the research aims of this study. Questions were either updated or removed and replaced by additional questions on sunshine exposure and dietary habits, ethnicity, UK residency, vitamin D levels, and mandatory food fortification. Occupational categories were deemed more appropriate than questions on income, and terms defined in a similar study by Kung and Lee (2006) were used. Ethnicity categorisation was taken from the Economic and Social Data Service Government publication (Afkhami, 2012), with the exception of the Arabic/Middle Eastern category, that was added to reflect the inclusion of this target group. The resulting survey consisted of 41 questions divided into four sections: demographics, vitamin D awareness and knowledge, sun exposure habits and dietary intake, and attitudes towards food fortification. Food groups were in the form of a short semi-quantitative Food Frequency Questionnaire (FFQ).

The study took place in Spring 2013. Participants were recruited from groups identified as being at risk of deficiency included: older adults aged over 65 years, South Asians, Blacks, 


\section{Knowledge of vitamin D}

110 Middle Eastern, Far Eastern, and a group of British Caucasians who do not avoid sun 111 exposure. This latter group was included so as to provide a comparison to a group who were 112 at a reduced risk of deficiency. Research was conducted in line with the university ethics 113 policy (approval obtained October 2012 - see supplementary material).

114 A screening questionnaire consisting of seven questions was also used to assign a target 115 group to each participant. All surveys were completed on paper hard copies. The majority of 116 surveys were completed face-to-face with a researcher with only a few exceptions, whereby 117 surveys were taken home by participants, and once completed surveys were either posted 118 back to the University or collected at a later date from community group locations by a 119 researcher. As the survey was only available in English assistance was offered in reading the 120 questions. This was provided by English speaking community group members in the presence 121 of a researcher so as to enable any questions to be asked.

\section{Study 2: Qualitative Pilot Study}

123 Qualitative methods were chosen for the second pilot study due to their ability to provide in124 depth information and elicit underlying reasoning from participants, something that is not 125 always possible during quantitative research (Threlfall, 1999). Both focus groups and 126 interviews were used.

127 Careful consideration was paid to controllable aspects known to contribute towards focus 128 group best practice, including focus group environment, the research team and participant 129 recruitment. Both focus groups and interviews were held on campus in Spring 2014, and were 130 recorded to enable transcription and subsequent analysis. A moderator and an assistant 131 researcher were also present to help record participant body language and facial expression, 132 to help inform the face validity of the results. 
Knowledge of vitamin D

133 Although debate still exists as to the best composition of focus groups, pre-existing friendship 134 groups were used in this research to make use of the "naturalistic exchanges" between 135 participants, and to encourage the disclosure of information.

136 Convenience, purposeful sampling was used to ensure that young South-Asian females were 137 recruited for the study. Participation was restricted to those who could speak English, but 138 there was no restriction on how long participants had resided in the UK. Awareness of the 139 focus groups was raised at three locations around campus known to be frequented by 140 international students, with students being invited to leave their contact details with 141 researchers so that they could be provided with more information

142 A semi-structured approach was taken, with a discussion guide being created from a detailed 143 literature review in relations to the aims of the investigation. Questions were asked to 144 establish participants' baseline awareness and attitudes towards vitamin D, sources and health 145 benefits, with further information provided about the health consequences of deficiency after 146 initial discussions were held.

147 Due to participant non-attendance at focus groups, two individual interviews were also 148 conducted using the same discussion guide as the focus groups. These provided a further 149 opportunity to explore participants' attitudes and knowledge, whilst not being affected by 150 group bias, a potential risk in focus groups (Threlfall, 1999).

151

152

153

154

155

156

\section{Data Analysis}

SPSS version 19.0 (SPSS, 2010) was used for analysis. Chi-square $\left(\chi^{2}\right)$ tests were used to examine associations between the study groups and the questions at the $5 \%$ significance level $(p<0.05)$. Analysis of the awareness of the health benefits of vitamin D and preference for voluntarily fortified foods included the study groups as a total group $(n=120)$. Therefore, no 
Knowledge of vitamin D

$157 \chi^{2}$ associations were made, however the frequency (and percentage) of the stated health 158 benefits are shown.

159 A thematic approach was taken to data analysis, which enabled key themes to be identified 160 and reported across data sets (Braun and Clarke, 2006) relevant to the aims of the study. After 161 having familiarised themselves with the transcripts researcher notes, codes were ascribed to 162 describe meaning of the data. These codes were then organised into themes that helped to 163 explain the codes, in relation to the research aims.

165 Results

166 Study 1

167 Demographics

168 Table 1 summarises participant demographic information in addition to their knowledge of 169 sunlight as a source of vitamin D. 120 completed surveys were obtained, by significantly 170 more females $(53 \%)$ than males $(45 \% ; p=0.001)$, with their being a significant differences 171 in age distribution across groups $(p=<0.001)$, period of residence in the UK $(p=<0.001)$, 172 occupation $(p<0.001)$, and highest level of education $(p<0.001)$ across groups. A similar 173 number of responses were obtained across at risk and the control groups as highlighted in 174 table 1.

175

176 Health benefits of vitamin D

177 Table 2 summarises awareness of the health benefits associated with vitamin D among the 178 whole group $(\mathrm{n}=120)$, with $\chi^{2}$ analysis was not performed on this question due to the 179 inclusion of the whole group. Bone health was the most common benefit mentioned, with $18037 \%$ of respondents stated that vitamin $\mathrm{D}$ is beneficial for this, with the next most frequent 181 categories being healthy skin (18\%) and general health/fitness (11\%). More specific health 
Knowledge of vitamin D

182 conditions, such as those listed in Table 2, were spontaneously associated by no more than $1838 \%$ of respondents each.

184

Risk Factors for vitamin D deficiency

186 The belief that inadequate sun exposure is a risk factor for vitamin D deficiency, was 187 significantly different between the groups $(p=0.037)$. South Asians were most likely to 188 know that inadequate sun exposure is a risk factor with $84 \%$ believing that it increased the 189 risk of deficiency, followed by the British Caucasian group (71\%). However, just $45 \%$ of 190 those over 65 years believed it increases risk whilst a further $40 \%$ did not know. This was also evident among Black respondents, whereby 50\% said it increases risk and $32 \%$ did not know.

Figure 1 highlights that awareness of natural darker skin pigmentation as a risk factor for vitamin $\mathrm{D}$ deficiency, was significantly different across groups $(p=0.023)$. Interestingly, almost half of South Asians (40\%) thought having natural darker skin pigmentation does not affect the risk of vitamin D deficiency, whilst half of the Black respondents did not know. A similar response was also found among Middle Eastern and British Caucasian respondents whereby just over half (52\%) said they did not know.

Awareness of inadequate dietary consumption as a risk factor for vitamin D deficiency, was not significantly different across groups $(p=0.174)$. The majority of the South Asian and British Caucasian groups believed it increases risk ( $80 \%$ and $71 \%$, respectively). However, there was much variation across the Middle Eastern group, in that $48 \%$ of respondents responding that it increases yet $43 \%$ did not know.

Although sun cream use was notable across the groups, over $40 \%$ of respondents in each group, except for Far Eastern respondents (only 27\%), did not know that using sun cream is a 


\section{Knowledge of vitamin D}

206 risk factor for deficiency. Few respondents in all groups said it increases risk, in the range of 207 2-3 respondents (data not shown).

208 Those over 65 years had the highest 'don't know' response as to whether inadequate sun 209 exposure is a risk factor for vitamin D deficiency; with 40\% who did not know whilst just $21045 \%$ said it increases risk. Likewise, 55\% did not know that using sun cream is a risk factor 211 for deficiency thereby suggesting that those over 65 years have limited awareness of vitamin 212 D.

213 Awareness and preference of fortification of foods with vitamin D

214 Over $60 \%$ respondents in each at risk group, in particular $90 \%$ of Black respondents, were 215 unaware of foods currently fortified with vitamin D. Interestingly the majority of the British 216 Caucasian group (71\%), as a group not as at-risk of deficiency, were aware of such foods. In 217 terms of preferences of fortified products, breakfast cereals were most preferred (64\%), 218 followed by cow's milk (58\%), fortified fruit juice (55\%) and margarine and spreads (47\%).

219 Mandatory fortification of some foods would be accepted by Blacks (68\%), those over 65 220 years (50\%), Middle Eastern respondents (67\%), and the Far Eastern respondents (73\%). 221 However, the Caucasian British group (71\% no) did not show acceptance whilst South Asians 222 gave a mixed response (48\% said yes, and 52\% said no). This was significantly different 223 between the groups $(p=0.004)$.

$224 \quad$ Study 2

225 In total three focus groups and two individual interviews were conducted on 16 South-Asian 226 females all under the age of 25, with nine students from South-Asian countries having lived 227 in the UK for less than a year.

228 General unawareness was a key theme to emerge across all focus groups and interviews in 229 relation to dietary sources and vitamin D's role in health, with the sun being cited as a source 
Knowledge of vitamin D

230 of vitamin D by the majority of participants. However, the long-known association with bone 231 health was less frequently identified by participants, although still the most frequently 232 mentioned health benefit. Participants were therefore shocked by some of the consequences 233 of vitamin D deficiency presented to them during the focus groups.

234 A number of participants, specifically those who had lived in the UK for less than a year, 235 were unable to identify a source of vitamin D, with others, again who were not long-term UK 236 residents, being unaware that vitamin D could be obtained from dietary sources, despite 237 correctly identifying the sun as the main source of vitamin D. This general theme of 238 unawareness also extended to participants' knowledge of at risk groups from vitamin D 239 deficiency, with participants admitting to not knowing who would be most at risk. 240 Interestingly, a small number of participants did cite pale skinned persons as being more at 241 risk of deficiency, when in fact the opposite is true.

242 For those who indicated some previous awareness of vitamin D the media was cited as the 243 main source, including recent advertising appeals;

As well as a general unawareness of vitamin $\mathrm{D}$, misconceptions also arose in relation to 249 dietary sources of vitamin D and the health benefits from achieving and obtaining adequate 250 vitamin D levels. This was highlighted by one participant citing that the main purpose of 251 vitamin D within the body was to induce a sun tan.

252 Participants were also unaware as to the key concepts associated with fortification with 253 "extra supplements" being the closest suggestions made by participants as to what 254 fortification entailed, with the majority being unsure, despite their awareness of fortified 
Knowledge of vitamin D

255 foods adverts on television, indicating that they may not be entirely aware of why products 256 are fortified.

257 In light of participants lack of knowledge of vitamin D, a definition of fortification was 258 provided in focus groups and interviews to enable participants' opinions on the subject to be 259 obtained. Subsequently views on fortification were categorised as a theme, in relation to both 260 voluntary and mandatory fortification, with the former being received in a positive light and 261 raising little concern;

"I would worry that it not natural and so, against nature and could be bad for you" Focus

"I think if they want to fortify foods with it, then they should probably put the nutrients in foods that intrinsically have similar properties that could contain such vitamins, because it wouldn't make sense if you put it in something that is not used to such kind of nutrition, it may cause some kind of imbalance” Focus Group1, Participant 2

The naturalness of fortification was raised as a concern, indicating a need to take this into consideration and use appropriate communications when marketing fortified foods;

Group 2, Participant7

Despite the general positive views towards voluntary fortification, mandatory fortification of foods with vitamin D received more of a mixed response with concerns being raised by individuals in relation to consumer choice and toxicity, the latter of which being raised in every focus group and interview indicating that it is not an isolated concern.

Despite the concerns raised in relation to fortification, most participants would prefer to consume fortified food products rather than take supplements, with the view that supplements were unnatural, inconvenient and seemed far too medical. 
Knowledge of vitamin D

285 Participants were asked to suggest specific foods that they would like to see fortified with a range of responses given including bread, milk and dairy products, vegetables, cereals, 287 chocolate, eggs and water. The range reflects their personal dietary preferences, with the 288 majority of participants reported consuming a diet that is a mixture of the two cultures, reflecting either a UK upbringing or current residential status in the UK, with selected food 290 products being mentioned due to participants' beliefs that they would benefit the population 291 as a whole e.g. bread and milk.

292

293

294

295

296

297

298

299

300

301

302

303

304

305

\section{Discussion}

This paper presents two pilot studies of the awareness of vitamin D and attitudes towards food fortification in at risk groups in the North East of England. Consideration of food fortification with vitamin $\mathrm{D}$ in order to improve vitamin $\mathrm{D}$ intakes at a population level have been proposed in the literature (Lamberg-Allardt, 2006, Kiely and Black, 2012, O'Mahony et al., 2011, Calvo and Whiting, 2006). Therefore, this study provides an insight into specific at risk consumers' attitudes and acceptance towards foods fortified with vitamin D as well as their awareness of vitamin D. This is particularly important research for research nutritionists, food manufacturers and scientists involved in setting public health nutrition policy.

The findings of this research support those in a study by Alemu and Varnam (2012), whereby minimal awareness was evident among men and older adults and they suggest age as an important factor in determining level of awareness. Similarly, Kung and Lee (2006) found a lack of awareness among older Chinese women, with awareness appearing to decrease in age. Farrar et al., (2011) indicated that there is a lack of data on sunshine exposure habits of UK South Asians and they suggest that South Asians may adopt less sun-seeking behaviours. Although the majority of participants across all groups knew that sunlight was a source of vitamin $\mathrm{D}$, most were unaware of the time required to obtain sufficient vitamin $\mathrm{D}$ from 


\section{Knowledge of vitamin D}

310 sunlight exposure. This lack of awareness, and avoidance of sun-seeking behaviours amongst

311 at-risk groups, indicates a need for greater communication of safe sun exposure information.

312 School was the major source of information for all the groups, bar the British Caucasians and

313 those over 65 years (data not shown), with the media also being cited as a key source of

314 information, especially for focus group participants where the media was the main source of

315 information, including recent adverts of fortified foods. These main sources of information

316 are similar to previous studies (Alemu and Varnam, 2012). This suggests school and media

317 have an important role in increasing awareness of vitamin D and sun exposure, and could be

318 key mediums for dissemination information for increasing vitamin D intakes.

319 Less than half of participants across all groups identified bone health as a benefit of optimum

320 vitamin D, which was reflected in the qualitative findings, with considerably fewer

321 participants being able to identify other benefits. This reflects previous research in Saudi

322 Arabia, where Christie and Mason (2011) found awareness of vitamin D benefits restricted to

323 musculoskeletal health. Although other health benefits were commonly reported in the

324 present study were healthy skin and general health/fitness, yet few participants did not know

325 that vitamin D was beneficial, again as evident in previous research (Bonevski et al., 2013).

326 This indicates that people are aware that vitamins in general are beneficial yet many are

327 unaware of the specific benefits associated with vitamins, in this case vitamin D. Given the

328 association of vitamin $\mathrm{D}$ with an increasing number of health conditions, conveying the

329 health benefits of ensuring vitamin D sufficiency to increase awareness would seem of

330 critical importance, given such limited awareness currently exists.

331 Further to the results indicating a lack of awareness of the benefits associated with vitamin D,

332 the findings from both studies indicate a lack of awareness, or inability of participants to

333 correctly identify at-risk factors for vitamin D deficiency, including factors that would put

334 themselves at risk, such as having a naturally darker skin pigmentation. This was particularly 


\section{Knowledge of vitamin D}

335 the case in the qualitative research for those who had lived in the UK for less than a year, 336 who had particularly limited awareness. Given that research has indicated several cases of 337 vitamin D deficiency in the UK in at-risk groups (Moy et al., 2012), ensuring that these 338 groups are reached with communications to enable themselves to identify as being at risk is 339 essential. Otherwise, at-risk individuals may not view fortified products, or supplements, as 340 relevant or necessary for themselves. This was exemplified in the results of the survey, with 341 the majority in all at risk groups being unaware of foods currently fortified with vitamin D. 342 However, the majority of the British Caucasian group (71\%), those at a reduced risk of 343 deficiency, were aware of such foods fortified with vitamin D. This indicates that current 344 fortified food products are not currently targeting those at risk of deficiency or are not 345 communicating effectively that they have been fortified. Given the potential for fortified 346 foods to increase vitamin D levels (Jääskeläinen et al., 2017), the identification of appropriate 347 foods to fortify for at risk groups is essential, and future research should look to explore this 348 in more depth, with more representative samples.

349 Results from both studies indicated no preference for products to be voluntarily fortified with 350 vitamin $\mathrm{D}$, with there also being no consensus over the influence of mandatory fortification in 351 purchasing staple products such cow's milk or bread, other than for the British Caucasian 352 group, who were not in favour.

353 The lack of preference for fortification of certain products, and for mandatory fortification in 354 general, may be partially explained by concerns raised during the qualitative research, in 355 relation to toxicity, consumer choice and naturalness. This reflects findings by Tedstone $e t$ 356 al., (2008) who found mandatory fortification of folic acid was generally accepted amongst 357 participants, although concerns regarding consumer safety and choice were raised. This 358 highlights a need for effective communication in relation to the safety of fortified products, 


\section{Knowledge of vitamin D}

359 and clear labelling, especially for voluntary fortification, to ensure consumer freedom of 360 choice is maintained.

\section{Recommendations}

362 Further research could include other groups at risk of deficiency such as pregnant women, 363 obese individuals, and care providers for those in institutionalised care. It would also be 364 interesting to increase the sample size so as to make inferences about whether a particular 365 factor influences the level of vitamin D awareness among these different at risk groups, and 366 to conduct more research into which foods would be the most appropriate and acceptable to 367 fortify to target those most at risk of vitamin D deficiency. Future research should also look 368 to establish the effect of conveying information on the health benefits of vitamin on 369 willingness-to-purchase and preferences for fortified products.

\section{Conclusion}

371 Food fortification with vitamin D is a promising approach to increase vitamin D intake in 372 countries and groups susceptible to vitamin D deficiency. Both these pilot studies identified a 373 distinct lack of awareness of vitamin D and fortified foods among at risk groups of the UK 374 population, although favourable attitudes towards fortification, particularly voluntary 375 fortification, were displayed. Further research, on a larger scale, is needed in this area to 376 enable a better understanding of the knowledge and attitudes of vitamin D and fortified foods 377 among these at risk groups so that the most effective public health policies can be introduced.

\section{Research Considerations}

Both studies are limited by small sample sizes, a result of the difficulties experienced whilst trying to recruit participants from the specific groups of the population within a limited time frame. Subsequently, future research should look to ensure larger, stratified samples to improve the results generalisability. In addition, years of residence in a country could be added to further explore any variations in attitudes and preferences this may bring. The 
Knowledge of vitamin D

400

401

402

403

404

405

406

407

408

409

410

411

412

413

414

415

416

417

418

419

420

421

422

423

sequence of questions could have been improved to reduce potential bias, in that questions on awareness and knowledge precede that of behaviour and attitudes. Therefore, participants may become more favourable towards fortification after answering questions on awareness and knowledge of vitamin $\mathrm{D}$, after realising they may not get adequate vitamin $\mathrm{D}$ themselves. For the qualitative study a more representative sample of the South Asian population could have been used, to encompass a wider range of ages and a mix of genders, thus enabling a more representative view of the populations' knowledge and attitudes to be obtained. However, both pieces of research present novel studies, into an area where there is limited research. The quantitative study design enabled a direct comparison between different ethnicities and the control group, with the qualitative study enabling more in-depth information to be obtained to further explore consumers' knowledge and attitudes.

\section{References}

AFKHAMI, R. 2012. Ethnicity: Introductory User Guide. In: SERVICE, E. A. S. D. (ed.). ESDS Governmemnt.

ALEMU, E. \& VARNAM, R. 2012. Awareness of vitamin D deficiency among at-risk patients. BMC research notes, 5, 17.

ASHWELL, M., STONE, E. M., STOLTE, H., CASHMAN, K. D., MACDONALD, H., LANHAM-NEW, S., HIOM, S., WEBB, A. \& FRASER, D. 2010. UK Food Standards Agency Workshop Report: an investigation of the relative contributions of diet and sunlight to vitamin D status. British Journal of Nutrition, 104, 603611.

BATES, B., LENNOX, A. M., PRENTICE, A., BATES, C. \& SWAN, G. 2012. National Diet and Nutrition Survey: Headline results from Years 1, 2 and 3 (combined) of the Rolling Programme (2008/2009 - 2010/11) [Online].

Available: https://www.gov.uk/government/uploads/system/uploads/attachment data/file/207708/NDNS-Y3report All-TEXT-docs-combined.pdf

BATTAULT, S., WHITING, S. J., PELTIER, S. L., SADRIN, S., GERBER, G. \& MAIXENT, J. M. 2013. Vitamin D metabolism, functions and needs: from science to health claims. European journal of nutrition, 52, 429-41.

BLACK, L. J., SEAMANS, K. M., CASHMAN, K. D. \& KIELY, M. 2012. An Updated Systematic Review and MetaAnalysis of the Efficacy of Vitamin D Food Fortification-. The Journal of nutrition, 142, 1102-1108.

BONEVSKI, B., BRYANT, J., LAMBERT, S., BROZEK, I. \& ROCK, V. 2013. The ABC of Vitamin D: A qualitative study of the knowledge and attitudes regarding vitamin d deficiency amongst selected population groups. Nutrients, 5, 915-927.

BORRADALE, D. \& KIMLIN, M. 2009. Vitamin D in health and disease: an insight into traditional functions and new roles for the 'sunshine vitamin'. Nutrition research reviews, 22, 118-136.

BOUCHER, B. J. 2012. The problems of vitamin d insufficiency in older people. Aging and disease, 3, 313-29.

BRAUN, V. \& CLARKE, V. 2006. Using thematic analysis in psychology. Qualitative research in psychology, 3, 77101.

CALVO, M. S. \& WHITING, S. J. 2006. Public health strategies to overcome barriers to optimal vitamin D status in populations with special needs. Journal of Nutrition, 136, 1135-1139.

CASHMAN, K. D. 2007. Diet, nutrition, and bone health. Journal of Nutrition, 137, 2507S-2512S. 
2

CASHMAN, K. D. 2012. The role of vitamers and dietary-based metabolites of vitamin D in prevention of vitamin D deficiency. Food \& nutrition research, 56.

CHOWDHURY, R., KUNUTSOR, S., VITEZOVA, A., OLIVER-WILLIAMS, C., CHOWDHURY, S., KIEFTE-DE-JONG, J. C., KHAN, H., BAENA, C. P., PRABHAKARAN, D. \& HOSHEN, M. B. 2014. Vitamin D and risk of cause specific death: systematic review and meta-analysis of observational cohort and randomised intervention studies. Bmj, 348, g1903.

CHRISTIE, F. T. E. \& MASON, L. 2011. Knowledge, attitude and practice regarding vitamin D deficiency among female students in Saudi Arabia: a qualitative exploration. International Journal of Rheumatic Diseases, 14, E22-E29.

FARRAR, M. D., KIFT, R., FELTON, S. J., BERRY, J. L., DURKIN, M. T., ALLAN, D., VAIL, A., WEBB, A. R. \& RHODES, L. E. 2011. Recommended summer sunlight exposure amounts fail to produce sufficient vitamin $D$ status in UK adults of South Asian origin. American Journal of Clinical Nutrition, 94, 1219-1224.

HOLICK, M. F. 2017. The vitamin D deficiency pandemic: Approaches for diagnosis, treatment and prevention. Reviews in Endocrine and Metabolic Disorders, 18, 153-165.

JÄÄSKELÄINEN, T., ITKONEN, S. T., LUNDQVIST, A., ERKKOLA, M., KOSKELA, T., LAKKALA, K., DOWLING, K. G., HULL, G. L. J., KRÖGER, H., KARPPINEN, J., KYLLÖNEN, E., HÄRKÄNEN, T., CASHMAN, K. D., MÄNNISTÖ, S. \& LAMBERG-ALLARDT, C. 2017. The positive impact of general vitamin D food fortification policy on vitamin $D$ status in a representative adult Finnish population: evidence from an 11-y follow-up based on standardized 25-hydroxyvitamin D data. The American Journal of Clinical Nutrition, 105, 15121520.

KIELY, M. \& BLACK, L. J. 2012. Dietary strategies to maintain adequacy of circulating 25-hydroxyvitamin D concentrations. Scandinavian journal of clinical and laboratory investigation. Supplementum, 243, 1423.

KIFT, R., BERRY, J., VAIL, A., DURKIN, M., RHODES, L. \& WEBB, A. 2013. Lifestyle factors including less cutaneous sun exposure contribute to starkly lower vitamin D levels in UK South Asians compared with the white population. British Journal of Dermatology, 169, 1272-1278.

KUNG, A. W. \& LEE, K.-K. 2006. Knowledge of vitamin D and perceptions and attitudes toward sunlight among Chinese middle-aged and elderly women: a population survey in Hong Kong. BMC public health, 6, 226.

LAMBERG-ALLARDT, C. 2006. Vitamin D in foods and as supplements. Progress in Biophysics \& Molecular Biology, 92, 33-38.

MCAREE, T., JACOBS, B., MANICKAVASAGAR, T., SIVALOKANATHAN, S., BRENNAN, L., BASSETT, P., RAINBOW, S. \& BLAIR, M. 2013. Vitamin D deficiency in pregnancy - still a public health issue. Maternal and Child Nutrition, 9, 23-30.

MEYER, H. E., HOLVIK, K., LOFTHUS, C. M. \& TENNAKOON, S. U. 2008. Vitamin D status in sri lankans living in sri lanka and norway. British journal of nutrition, 99, 941-944.

MOY, R. J., MCGEE, E., DEBELLE, G. D., MATHER, I. \& SHAW, N. J. 2012. Successful public health action to reduce the incidence of symptomatic vitamin D deficiency. Archives of Disease in Childhood, 97, 952954.

O'MAHONY, L., STEPIEN, M., GIBNEY, M. J., NUGENT, A. P. \& BRENNAN, L. 2011. The Potential Role of Vitamin D Enhanced Foods in Improving Vitamin D Status. Nutrients, 3, 1023-1041.

PALACIOS, C. \& GONZALEZ, L. 2014. Is vitamin D deficiency a major global public health problem? The Journal of Steroid Biochemistry and Molecular Biology, 144, 138-145.

PEARCE, S. \& CHEETHAM, T. D. 2010. Diagnosis and management of vitamin D deficiency. Bmj, 340, b5664.

REEDER, A. I., JOPSON, J. A. \& GRAY, A. R. 2012. "Prescribing sunshine": a national, cross-sectional survey of 1,089 New Zealand general practitioners regarding their sun exposure and vitamin D perceptions, and advice provided to patients. Bmc Family Practice, 13.

SACN. 2016. Vitamin $D$ and Health [Online]. Crown Copyright. Available: https://www.gov.uk/government/publications/sacn-vitamin-d-and-health-report

SPSS 2010. SPSS Statistics for Windows. 19.0 ed. Chicago, IL, USA: SPSS Inc.

TEDSTONE, A., BROWNE, M., HARROP, L., VERNON, C., PAGE, V., SWINDELLS, J., HAYWARD, W., CROFT, J., HARRIS, F. \& STOCKLEY, L. 2008. Fortification of selected foodstuffs with folic acid in the UK: consumer research carried out to inform policy recommendations. Journal of Public Health, 30, 23-29.

THRELFALL, D. K. 1999. Using focus groups as a consumer research tool. Journal of Marketing Practice: Applied Marketing Science, 5, 102-105. 
Knowledge of vitamin D

1

2

3

4

5

6

7

8

9

10

11

12

13

14

15

16

17

18

19

20

21

22

23

24

25

26

27

28

29

30

31

32

33

34

35

36

37

38

39

40

41

42

43

44

45

46

47

48

49

50

51

52

53

54

55

56

57

58

59

60 
Table 1: Demographic and sample size information for each group of survey participants

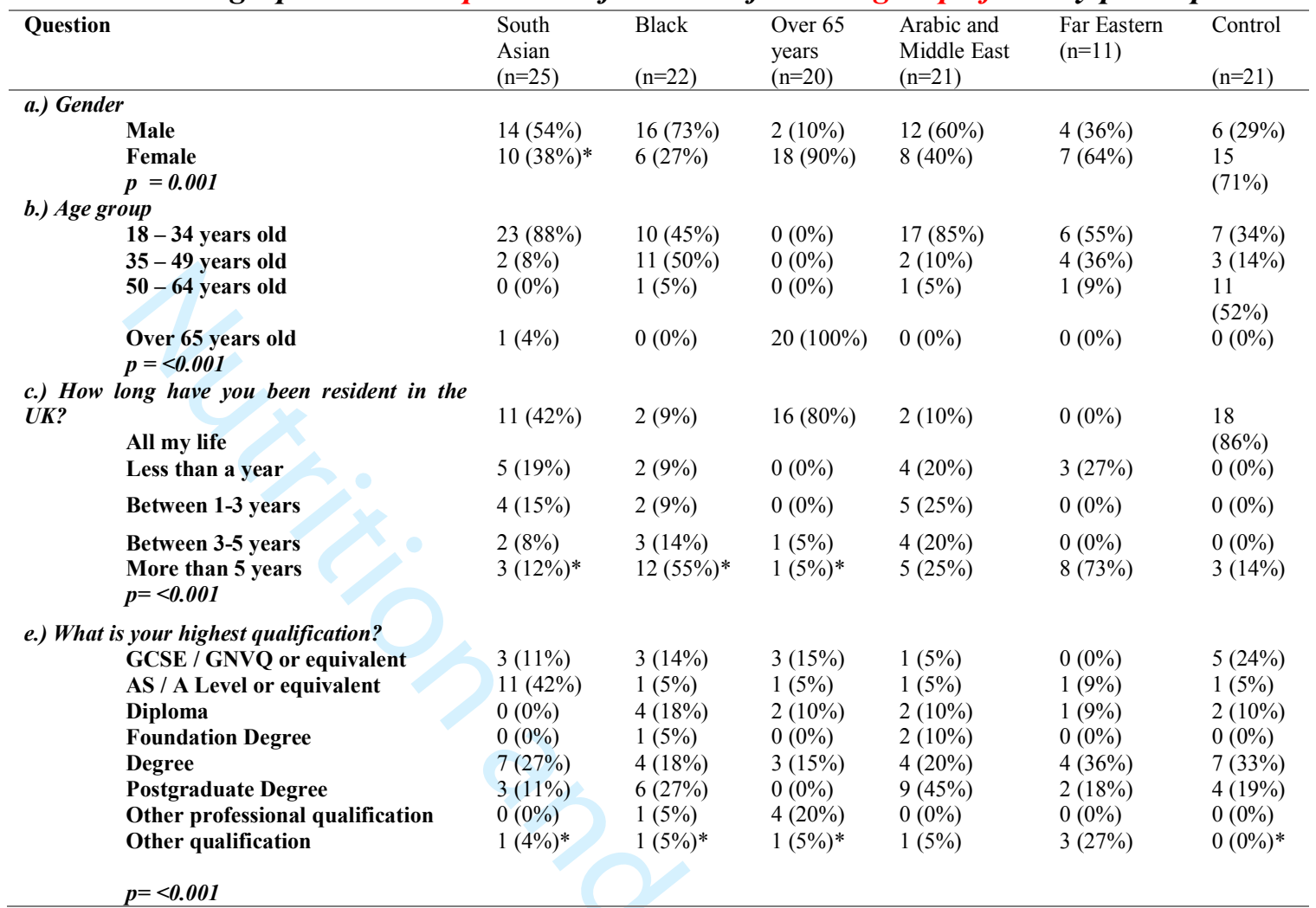

*Responses for some questions do not add up to $100 \%$ due to participants declining to provide this information.

GCSE - General Certificate of Secondary Education; GNVQ - General National Vocational Qualification; AS/A levels -Advanced Subsidiary/ Advanced level

Data across groups was compared with a Chi-Square test 
Table 2: Health benefits associated with vitamin D as listed by survey participants

\begin{tabular}{lll}
\hline What health benefits do you associate with vitamin D? & $\begin{array}{l}\text { Number participants } \\
\text { citing the benefit } \\
(\mathbf{n}=\mathbf{1 2 0})\end{array}$ & $\begin{array}{l}\text { Percentage } \\
\text { participants } \\
\text { citing the benefit } \\
\mathbf{( \% )}\end{array}$ \\
\hline Bone Health & 44 & $37 \%$ \\
Healthy skin & 21 & $18 \%$ \\
General health/fitness & 13 & $11 \%$ \\
Mental health/cognition/improves mood & 10 & $8 \%$ \\
Absorption of calcium & 8 & $7 \%$ \\
Hair and nails & 8 & $7 \%$ \\
Strong teeth & 7 & $6 \%$ \\
Energy & 5 & $4 \%$ \\
Healthy immune system & 4 & $3 \%$ \\
Joints & 3 & $3 \%$ \\
Eyesight & 3 & $3 \%$ \\
Prevent cancer & 3 & $3 \%$ \\
Regulates blood pressure & 3 & $3 \%$ \\
Muscle strength & 2 & $2 \%$ \\
Normal neurological function & 2 & $2 \%$ \\
Well-balanced diet & 1 & $1 \%$ \\
Storage of calcium & 1 & $1 \%$ \\
Normal liver function & 1 & $1 \%$ \\
Protection from sunburn & 1 & $1 \%$ \\
Helps reduce weight & 1 & $1 \%$ \\
Melanin synthesis & 1 & $1 \%$ \\
Thin legs and big belly if lack of vitamin D & 1 & $1 \%$ \\
\hline
\end{tabular}

All responses were provided as free text entries in the survey, and grouped together based on the type of benefit mentioned. 
Figure 1: The number of survey participants who believe that darker skin pigmentation is a risk factor for vitamin D deficiency ( $p=0.023$ )

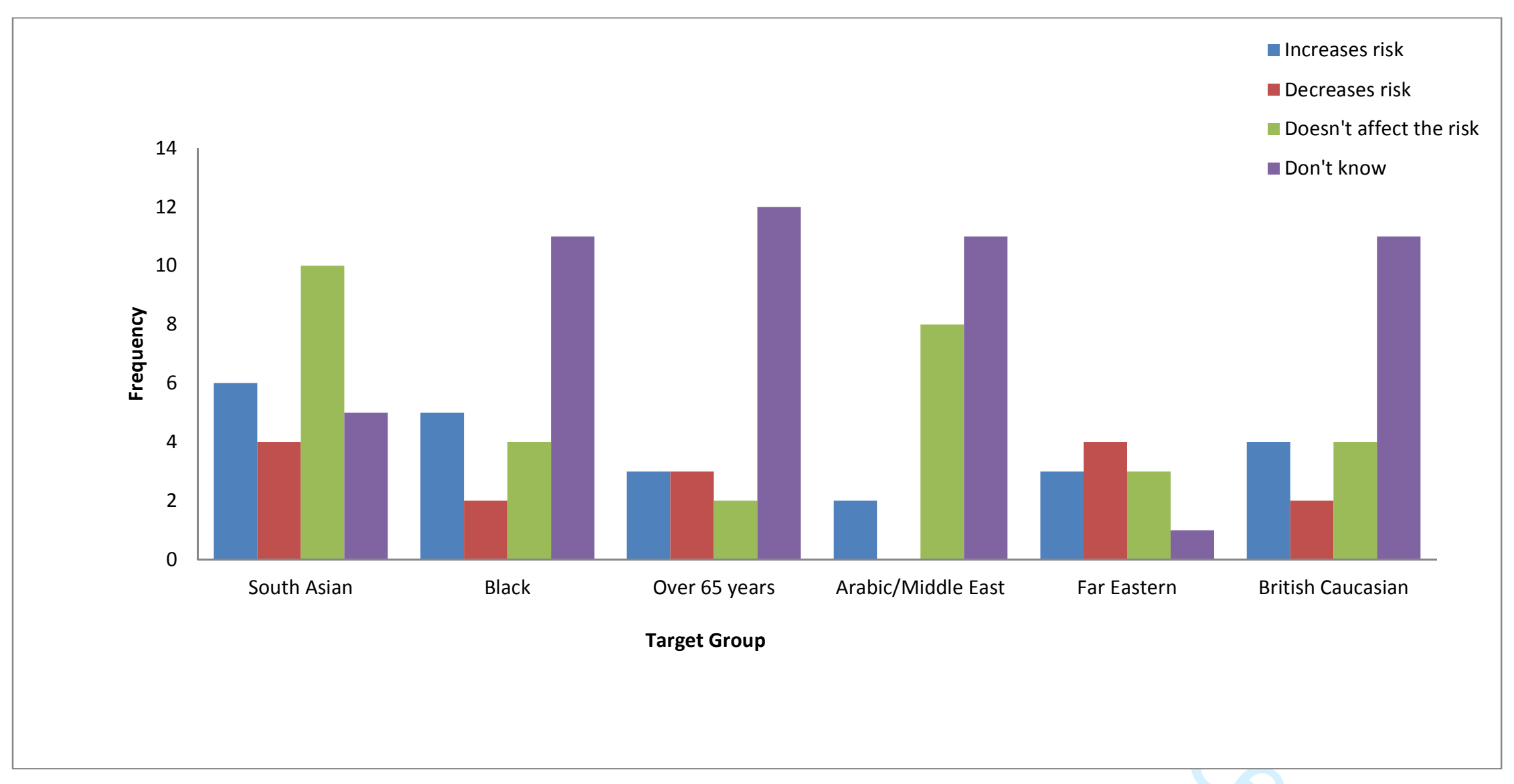

Comparison across groups was made using a Chi-Square test 
Table 3: Acceptance rates for the mandatory fortification of foods with vitamin $D$ by survey participants, as indicated by the percentage responding yes to each statement.

\begin{tabular}{|c|c|c|c|c|c|c|c|}
\hline 4 & $\begin{array}{l}\text { South } \\
\text { Asians }\end{array}$ & Blacks & $\begin{array}{c}\text { Over } 65 \\
\text { years }\end{array}$ & $\begin{array}{l}\text { Arabic/ } \\
\text { Middle } \\
\text { Eastern }\end{array}$ & $\begin{array}{c}\text { Far } \\
\text { Eastern }\end{array}$ & $\begin{array}{c}\text { Caucasian } \\
\text { British }\end{array}$ & $\begin{array}{c}\text { Chi square } \\
\text { result }\end{array}$ \\
\hline $\begin{array}{l}\text { If the government introduced law to fortify some } \\
\text { foods with vitamin D, would this influence your } \\
\text { choice of purchasing these foods?* }\end{array}$ & $48 \%$ & $68 \%$ & $50 \%$ & $67 \%$ & $73 \%$ & $29 \%$ & $p=0.004$ \\
\hline $\begin{array}{c}\text { If the government introduced law to fortify all } \\
\text { cow's milk with vitamin D, would this influence } \\
\text { your choice of purchasing this food? }\end{array}$ & $36 \%$ & $55 \%$ & $50 \%$ & $57 \%$ & $73 \%$ & $29 \%$ & $p=0.004$ \\
\hline $\begin{array}{l}\text { If the government introduced law to fortify all } \\
\text { UK varieties of bread with vitamin D, would this } \\
\text { influence your choice of purchasing this food? }\end{array}$ & $40 \%$ & 550 & $30 \%$ & $52 \%$ & $73 \%$ & $33 \%$ & $p=0.003$ \\
\hline
\end{tabular}

Comparisons across groups was made using a Chi-Square test 